Original Article

\title{
Influence of Taekwondo as Security Martial Arts Training on Anaerobic Threshold, Cardiorespiratory Fitness, and Blood Lactate Recovery
}

\author{
Dae-Young Kim, $\mathrm{PhD}^{1)}$, Byoung-Do Seo, MS, PT $\left.{ }^{2}\right)^{*}$, Pan-Am Choi, $\mathrm{PhD}^{3)}$ \\ 1) Department of Physiology, College of Medicine, Kyung Hee University, Republic of Korea \\ 2) Department of Physical Therapy, College of Health, Kyungwoon University: 55 Induck-ri, \\ Sandong-myeon, Gumi-si, Gyeongsangbuk-do 730-739, Republic of Korea \\ 3) Research Institute of Sport Science, Department of Protection Science, Kyungwoon University, \\ Republic of Korea
}

\begin{abstract}
Purpose] This study was conducted to determine the influence of Taekwondo as security martial arts training on anaerobic threshold, cardiorespiratory fitness, and blood lactate recovery. [Subjects and Methods] Fourteen healthy university students were recruited and divided into an exercise group and a control group $(\mathrm{n}=7$ in each group). The subjects who participated in the experiment were subjected to an exercise loading test in which anaerobic threshold, value of ventilation, oxygen uptake, maximal oxygen uptake, heart rate, and maximal values of ventilation / heart rate were measured during the exercise, immediately after maximum exercise loading, and at $1,3,5,10$, and $15 \mathrm{~min}$ of recovery. [Results] At the anaerobic threshold time point, the exercise group showed a significantly longer time to reach anaerobic threshold. The exercise group showed significantly higher values for the time to reach $\mathrm{VO}_{2 \max }$, maximal values of ventilation, maximal oxygen uptake and maximal values of ventilation / heart rate. Significant changes were observed in the value of ventilation volumes at the 1- and 5-min recovery time points within the exercise group; oxygen uptake and maximal oxygen uptake were significantly different at the 5and 10-min time points; heart rate was significantly different at the 1- and 3-min time points; and maximal values of ventilation / heart rate was significantly different at the 5-min time point. The exercise group showed significant decreases in blood lactate levels at the 15- and 30-min recovery time points. [Conclusion] The study results revealed that Taekwondo as a security martial arts training increases the maximal oxygen uptake and anaerobic threshold and accelerates an individual's recovery to the normal state of cardiorespiratory fitness and blood lactate level. These results are expected to contribute to the execution of more effective security services in emergencies in which violence can occur.

Key words: Security martial arts, Taekwondo, Anaerobic threshold
\end{abstract}

(This article was submitted Aug. 26, 2013, and was accepted Oct. 16, 2013)

\section{INTRODUCTION}

Taekwondo has high value as a security martial arts training technique due to its scientific basis and educational and physical training effects. Highly trained professional security guards use their bodies as a weapon, which helps them to perform their security services, and the combination of security techniques and martial arts maneuvers enables them to react efficiently to given situations. Sport scientists have developed and applied logical and effective training programs using Taekwondo as a martial arts training technique. Further, they have identified the physiologi-

*Corresponding author. Byoung-Do Seo (E-mail: oksbd@ naver.com)

(C2014 The Society of Physical Therapy Science. Published by IPEC Inc. This is an open-access article distributed under the terms of the Creative Commons Attribution Non-Commercial No Derivatives (by-ncnd) License $<$ http://creativecommons.org/licenses/by-nc-nd/3.0/>. cal limitations of exercise capacities and conducted various studies to predict and assess the exercise abilities of security personnel who know martial arts ${ }^{1)}$.

Among these factors, the anaerobic threshold (AT) is an important indicator for objective assessment of the functional capacity attained through Taekwondo training. Individuals with a high AT are capable of generating energy by using organic metabolism even during high-intensity exercises. This ability delays the onset of muscle fatigue and enables the continuation of high-intensity exercises ${ }^{2}$. For this reason, the AT is an important criterion for judging whether to continue or stop an exercise.

Cardiorespiratory fitness (CRF) is another excellent indicator for assessing cardiorespiratory system performance by using a maximum exercise-loading test and heart rate (HR) recovery ${ }^{3}$. One report stated that individuals who train regularly recover their resting HR after maximum exercise loading more rapidly than those who do not train ${ }^{4}$. This is attributable to autonomic nervous system activa- 
Table 1. Physical characteristics of the participants in the experiment

\begin{tabular}{lccccc}
\hline Variable & $\begin{array}{c}\text { Age } \\
(\text { years })\end{array}$ & $\begin{array}{c}\text { Height } \\
(\mathrm{cm})\end{array}$ & $\begin{array}{c}\text { Weight } \\
(\mathrm{kg})\end{array}$ & $\begin{array}{c}\text { BMI } \\
\left(\mathrm{kg} / \mathrm{m}^{2}\right)\end{array}$ & $\begin{array}{c}\text { Body fat } \\
(\%)\end{array}$ \\
\hline Untrained & $22.1 \pm 1.2$ & $173.8 \pm 3.1$ & $71.0 \pm 3.4$ & $23.5 \pm 0.7$ & $17.3 \pm 3.2$ \\
Trained & $22.0 \pm 0.8$ & $173.5 \pm 3.1$ & $72.6 \pm 5.7$ & $24.0 \pm 1.6$ & $18.8 \pm 4.4$ \\
\hline
\end{tabular}

Data are means $\pm \mathrm{SD}$; BMI, body mass index

tion $^{5)}$. Autonomic nervous system responses to physical movements are governed by the parasympathetic nerves in the resting state, while sympathetic nerve activation occurs during exercise. Inversely, when the body is gradually brought back to the resting state after exercise, the parasympathetic nerves gradually become dominant again ${ }^{6}$. Practitioners of Taekwondo are well aware of this nervous system mechanism, and their HR recovery capacities are known to be superior. The HR decreases rapidly during the first 1-2 min after maximum exercise loading, while the recovery speed decreases after $3 \mathrm{~min}^{7}$.

The ability to remove blood lactate indicates an individual's ability to perform an endurance exercise or continue exercising more intensely ${ }^{8}$. An increase in lactate removal ability translates into decreased lactate accumulation during exercise, not only in the blood but also in the activated muscles; this phenomenon is conducive to recovering cell homeostasis and increasing recovery capacity ${ }^{9}$.

While several studies have assessed HR within the 3or 5-min recovery period and investigated how it correlates with the AT, few studies have investigated respiratory, HR, and blood lactate recovery responses in detail. Further, by investigating $\mathrm{CRF}$ and lactate recovery capacity as blood fatigue markers, information can be obtained about which is required for emergency responders to manage situations that are likely to occur during intense and repeated Taekwondo training for security martial arts. The results of this study are expected to provide basic physiological data to improve security services. With this purpose in mind, this study was conducted to determine the effect of Taekwondo training on the recovery of AT, CRF, and blood lactate to resting levels.

\section{SUBJECTS AND METHODS}

The subjects of this study were 14 healthy male university students aged 20-23 years with no medical diseases and no history of drug abuse. The exercise group $(n=7)$ comprised security majors who had been regularly practicing Taekwondo for $>3$ years, while the control group $(n=7)$ consisted of general university students with no martial arts experience, including Taekwondo, during the preceding 3 years. All subjects were educated about the contents and purpose of the experiment prior to its beginning and were asked to provide written informed consent prior to participating. The Kyungwoon University ethics review board approved this study, which complies with the Declaration of Helsinki principles.

The subjects' body heights $(\mathrm{cm})$ and weights $(\mathrm{kg})$ were measured by using an automatic measurement device (DS102; Jenix, Seoul, Korea), and their body mass indices
$(\mathrm{BMI})$ were calculated by using the equation $\mathrm{BMI}=$ weight $(\mathrm{kg}) /$ height $\left(\mathrm{m}^{2}\right)$. Body fat percentage was analyzed by using a BMI measuring device (InBody 4.0; Biospace, Seoul, Korea) that employs the bioelectrical impedance method. The subjects' physical characteristics are listed in Table 1.

Exercise testing consisted of minute ventilation (VE), oxygen uptake $\left(\mathrm{VO}_{2}\right)$, maximal oxygen uptake $\left(\mathrm{VO}_{2 \mathrm{max}}\right)$, $\mathrm{HR}$, and oxygen pulse $\left(\mathrm{O}_{2}\right.$ pulse $)$; measurements were obtained during the exercise, immediately after the maximum exercise loading, and at $1,3,5,10$, and $15 \mathrm{~min}$ of recovery. The measurements were taken by using a treadmill and metabolic gas analyzer system (Quark b ${ }^{2}$ Cosmed, Italy). The maximum exercise-loading test was performed by using the Bruce protocol. In compliance with the American College of Sports Medicine guidelines ${ }^{6}$, the maximum capacity was considered reached when the respiratory exchange ratio was $>1.15$ and the rate of perceived exertion was $>17$, when the $\mathrm{VO}_{2}$ value no longer increased with increasing exercise intensity, or when the subject wished to stop.

The $\mathrm{O}_{2}$ pulse was calculated by dividing the $\mathrm{VO}_{2}$ by the $\mathrm{HR}\left(\mathrm{O}_{2}\right.$ pulse $\left.=\mathrm{VO}_{2} / \mathrm{HR}\right)$ during the exercise testing and recovery. Postexercise recovery was induced by having the subject walk lightly (speed, $1.3 \mathrm{mph}$; gradient, $0 \%$ ) for 30 sec immediately after the exercise period; after the treadmill halted completely, the respiratory rate and HR were measured for 15 min with the subject sitting on a chair. HR was monitored with electrocardiography, and respiratory variables were measured by using the expired gas metabolism analysis system. The ventilation threshold (VT) necessary for the AT assessment was determined by using the modified V-slope method. The VT was determined to be the time point at which $\mathrm{VO}_{2}$ started to increase nonlinearly in relation to the $\mathrm{VCO}_{2}$. Blood lactate concentrations were measured with a lactate analyzer (Lactate Pro-LT1710; Arkray, Inc.) during the exercise, immediately after maximum exercise loading, and at $1,3,5,10$, and 15 min of recovery.

Data analysis was performed by using independent $\mathrm{t}$ tests to compare the intergroup differences in the change in average values. To express the intergroup differences at each time point, $\Delta \%=[$ (exercise group - control group $) /$ control group $\times 100$ ] was calculated. Statistical significance was tested by using the PASW Statistics for Windows 18.0 software package (SPSS Inc., Chicago, IL, USA) at the level of $\alpha=0.05$.

\section{RESULTS}

At the AT time point, the exercise group showed a significantly longer mean time to reach AT (RAT) value than 
Table 2. Comparison of cardiorespiratory fitness-related variables at the anaerobic threshold time point

\begin{tabular}{lcc}
\hline Variable & Untrained & Trained \\
\hline RAT $(\mathrm{sec})$ & $493.5 \pm 24.7$ & $543.5 \pm 54.0^{*}$ \\
$\mathrm{VE}(1 / \mathrm{min})$ & $66.7 \pm 6.2$ & $71.5 \pm 6.7$ \\
$\mathrm{VO}_{2}(\mathrm{ml} / \mathrm{min})$ & $2958.8 \pm 493.8$ & $3164.5 \pm 518.9$ \\
$\mathrm{VO}_{2 \max }(\mathrm{ml} / \mathrm{kg} / \mathrm{min})$ & $41.6 \pm 6.9$ & $44.5 \pm 7.3$ \\
$\mathrm{HR}(\mathrm{bpm})$ & $139.1 \pm 5.7$ & $142.0 \pm 4.6$ \\
$\mathrm{O}_{2}$ pulse $(\mathrm{ml} / \mathrm{bpm})$ & $21.2 \pm 3.3$ & $22.2 \pm 3.5$ \\
\hline
\end{tabular}

${ }^{*} \mathrm{p}<0.05 ; * * \mathrm{p}<0.01 ; * * * \mathrm{p}<0.001 ;$ RAT, time to reach AT, VE, minute ventilation; $\mathrm{VO}_{2}$, oxygen uptake; $\mathrm{VO}_{2 \max }$, maximal oxygen uptake; $\mathrm{HR}$, heart rate; $\mathrm{O}_{2}$ pulse, $\mathrm{VO}_{2} / \mathrm{HR}$
Table 3. Comparison of cardiorespiratory fitness-related variables at the maximum exercise loading time point

\begin{tabular}{lcc}
\hline Variable & Untrained & Trained \\
\hline $\mathrm{RVO}_{2 \max }(\mathrm{sec})$ & $829.2 \pm 52.4$ & $904.2 \pm 61.0^{*}$ \\
$\mathrm{VE}_{\max }(1 / \mathrm{min})$ & $123.4 \pm 7.7$ & $137.8 \pm 8.8^{* *}$ \\
$\mathrm{VO}_{2}(\mathrm{ml} / \mathrm{min})$ & $3884.8 \pm 124.1$ & $4912.8 \pm 399.5^{* * *}$ \\
$\mathrm{VO}_{2 \max }(\mathrm{ml} / \mathrm{kg} / \mathrm{min})$ & $53.7 \pm 3.4$ & $67.0 \pm 5.0^{* * *}$ \\
$\mathrm{HR}_{\max }(\mathrm{bpm})$ & $180.2 \pm 5.5$ & $182.2 \pm 4.9$ \\
$\mathrm{O}_{2}$ pulse $(\mathrm{ml} / \mathrm{bpm})$ & $21.5 \pm 0.8$ & $26.9 \pm 2.4^{* * *}$ \\
\hline$* \mathrm{p}<0.05 ; * * \mathrm{p}<0.01 ; * * * \mathrm{p}<0.001 ; \mathrm{RVO}_{2 \max }$, time to reach $\mathrm{VO}_{2 \max } ;$ \\
$\mathrm{VE}_{\max }$, maximal values of ventilation; $\mathrm{VO}_{2}$, oxygen uptake; $\mathrm{VO}-$ \\
$2 \max$, maximal oxygen uptake; $\mathrm{HR}_{\max }$, maximal heart rate; $\mathrm{O}_{2}$ \\
pulse, $\mathrm{VO}_{2} / \mathrm{HR}$
\end{tabular}

Table 4. Comparison of cardiorespiratory fitness-related variables at the recovery time points

\begin{tabular}{lcccccccccc}
\hline \multirow{2}{*}{ Variable } & \multicolumn{2}{c}{$1 \mathrm{~min}$} & \multicolumn{2}{c}{$3 \mathrm{~min}$} & \multicolumn{2}{c}{$5 \mathrm{~min}$} & \multicolumn{2}{c}{$10 \mathrm{~min}$} & \multicolumn{2}{c}{$15 \mathrm{~min}$} \\
\cline { 2 - 11 } & Untrained & Trained & Untrained & Trained & Untrained & Trained & Untrained & Trained & Untrained & Trained \\
\hline \multirow{2}{*}{$\mathrm{VE}(1 / \mathrm{min})$} & 96.9 & 78.0 & 44.4 & 43.4 & 37.9 & 31.6 & 24.3 & 23.0 & 15.7 & 14.7 \\
& \pm 9.7 & $\pm 16.7^{*}$ & \pm 3.4 & \pm 5.9 & \pm 4.3 & $\pm 2.1^{*}$ & \pm 3.8 & \pm 2.2 & \pm 1.5 & \pm 2.3 \\
$\mathrm{VO}_{2}(\mathrm{ml} / \mathrm{min})$ & 2826.4 & 2373.7 & 972.0 & 894.5 & 811.4 & 720.4 & 671.1 & 600.7 & 520.0 & 493.5 \\
& \pm 533.2 & \pm 171.2 & \pm 80.9 & \pm 119.8 & \pm 44.1 & $\pm 31.8^{*}$ & \pm 54.7 & $\pm 34.9^{*}$ & \pm 31.7 & \pm 76.3 \\
$\mathrm{VO}_{2 \max }(\mathrm{ml} / \mathrm{kg} / \mathrm{min})$ & 39.7 & 33.8 & 14.0 & 12.7 & 12.1 & 10.2 & 10.0 & 8.5 & 7.3 & 6.3 \\
& \pm 5.7 & \pm 16.7 & \pm 1.0 & \pm 1.7 & \pm 1.3 & $\pm 1.4^{*}$ & \pm 1.4 & $\pm 0.5^{*}$ & \pm 1.3 & \pm 1.1 \\
$\mathrm{HR}(\mathrm{bpm})$ & 159.5 & 137.5 & 110.5 & 104.0 & 102.5 & 98.8 & 94.2 & 91.7 & 83.0 & 78.8 \\
& \pm 12.2 & $\pm 17.5^{*}$ & \pm 5.6 & $\pm 4.0^{*}$ & \pm 9.8 & \pm 4.9 & \pm 6.3 & \pm 4.6 & \pm 6.8 & \pm 5.4 \\
\multirow{2}{*}{$\mathrm{O}_{2}$ pulse $(\mathrm{ml} / \mathrm{bpm})$} & 17.5 & 16.6 & 8.7 & 8.5 & 7.9 & 7.2 & 7.1 & 6.5 & 6.3 & 6.2 \\
& \pm 2.1 & \pm 6.1 & \pm 0.6 & \pm 0.8 & \pm 0.6 & $\pm 0.3^{*}$ & \pm 0.7 & \pm 0.2 & \pm 0.7 & \pm 1.1 \\
\hline
\end{tabular}

VE, minute ventilation; $\mathrm{VO}_{2}$, oxygen uptake; $\mathrm{VO}_{2 \max }$, maximal oxygen uptake; HR, heart rate; $\mathrm{O}_{2}$ pulse, $\mathrm{VO}_{2} / \mathrm{HR}$; *Significant difference between groups $(\mathrm{p}<0.05)$

the control group $(\mathrm{p}=0.04)$. No significant differences were observed in $\mathrm{VE}, \mathrm{VO}_{2}, \mathrm{VO}_{2 \max }, \mathrm{HR}$, or $\mathrm{O}_{2}$ pulse (Table 2). At the maximum exercise loading time point, the exercise group showed significantly higher values for time to reach $\mathrm{VO}_{2 \max }\left(\mathrm{RVO}_{2 \max }\right)(\mathrm{p}=0.03)$. The exercise group also showed a significantly higher maximal values of ventilation $\left(\mathrm{VE}_{\max }, \mathrm{p}=0.01\right), \mathrm{VO}_{2}(\mathrm{p}=0.01), \mathrm{VO}_{2 \max }(\mathrm{p}=0.01)$, and $\mathrm{O}_{2}$ pulse $(p=0.01)$. No significant differences were observed in the maximal heart rate ( $\mathrm{HR}_{\text {max }}$, Table 3 ).

The analysis results regarding recovery after maximum exercise loading revealed that the VE of the exercise group was significantly lower than that of the control group at $1 \min (\mathrm{p}=0.02)$ and $5 \mathrm{~min}(\mathrm{p}=0.01)$ of recovery. $\mathrm{VO}_{2}$ and $\mathrm{VO}_{2 \max }$ were significantly different at the $5 \min (\mathrm{p}=0.01)$ and $10 \mathrm{~min}(\mathrm{p}=0.02)$ time points, HR was significantly lower at the $1 \mathrm{~min}(\mathrm{p}=0.01)$ and $3-\min (\mathrm{p}=0.02)$ time points, and $\mathrm{O}_{2}$ pulse was significantly lower at the 5-min (p $=0.02)$ time point $($ Table 4$)$.

No significant changes in blood lactate levels were observed in the exercise group compared with the control group before or immediately after exercise, whereas it decreased significantly at the $15-(\mathrm{p}=0.01)$ and $30-\mathrm{min}(\mathrm{p}=$ $0.01)$ recovery time points (Table 5).
Table 5. Changes in blood lactate level

\begin{tabular}{lcc}
\hline Variable & Untrained & Trained \\
\hline Before exercise & $2.6 \pm 0.3$ & $2.8 \pm 0.5$ \\
After exercise & $10.9 \pm 1.0$ & $11.2 \pm 1.6$ \\
After 15 min & $7.8 \pm 0.9$ & $5.4 \pm 1.2^{* *}$ \\
After 30 min & $6.5 \pm 0.6$ & $4.5 \pm 0.7^{* * *}$ \\
\hline${ }^{*}<0.05 ; * * \mathrm{p}<0.01 ; * * * \mathrm{p}<0.001$ & $($ Unit: $\mathrm{mmol} / \mathrm{L})$
\end{tabular}

\section{DISCUSSION}

As shown in the study results, at the AT time point, the RAT was longer in the exercise group than in the control group. This finding signifies that regular exercise training increases AT, that an exercise of higher intensity can be performed after training, and that higher $\mathrm{VO}_{2}$ occurs without full recovery of the resting-state lactate level. Even with the increase in $\mathrm{VO}_{2 \max }$, the AT appears at a higher level after training. Kinderman et al. ${ }^{10)}$ stated that the AT is an important factor in choosing the optimal exercise intensity. Kumagai et al. ${ }^{11)}$ reported that exercise performance is more closely related to the $\mathrm{VO}_{2}$ at the AT than to the $\mathrm{VO}_{2 \max }$. At the maximum exercise loading time point, all variables, namely $\mathrm{RVO}_{2 \max }, \mathrm{VE}_{\max }, \mathrm{VO}_{2}, \mathrm{VO}_{2 \max }$, and $\mathrm{O}_{2}$ pulse, were higher. The finding that Taekwondo practitioners have su- 
perior CRF-related variables at the maximum exercise loading time point suggests that they can execute high-endurance exercises at a higher intensity and pace.

An individual's CRF level is their capacity to supply sufficient amounts of oxygen to meet increasing oxygen demands of activated muscles. An individual's endurance level depends on this capacity. Muscular endurance training such as Taekwondo practiced as security martial arts increases the efficiency of the oxygen transport system. In particular, the $\mathrm{O}_{2}$ pulse is the value obtained by dividing $\mathrm{VO}_{2 \max }$ by $\mathrm{HR}$ and denotes the amount of oxygen supplied by each heartbeat. Therefore, it is used as an indicator of circulatory system efficacy. Because it is related to the difference between arterial and venous blood oxygen pressure differences, which is tantamount to the arteriovenous oxygen content difference, along with cardiac output, it can indirectly assess the amount of oxygen extracted from the activated muscles ${ }^{12}$. The finding of this study that $\mathrm{O}_{2}$ pulse at the maximum exercise loading time point was significantly higher in the exercise group implies that Taekwondo practitioners demonstrate a superior capacity to supply adequate oxygen to their tissues and extract oxygen from activated muscles during training. This may be attributable to the increase in blood flow and density in the peripheral skeletal muscles, greater opening of the capillary vessels, and the arteriovenous oxygen content difference in the muscles activated because of the mutual adaptation of muscle and peripheral tissue induced by continuous training.

At the maximal exercise loading time point, the recovery CRF-related variables appeared to be higher in the Taekwondo practitioners undergoing regular training. This result may be explained by the increased vascular elasticity, control of the autonomic nervous system, and functional adaptation of the cardiorespiratory system with the increase in aerobic power because of regular training ${ }^{13}$. In particular, while most CRF-related variables showed significant differences until the 5-min recovery time point, $\mathrm{VO}_{2}$ values were significantly different up to the 10-min recovery time point. This result signifies that Taekwondo practitioners have higher respiratory rate recovery capacities than non-practitioners, as their respiration rate recovery curves reached the resting state more rapidly.

Observations of the changes in blood lactate level revealed that the exercise group had a higher lactate removal ability at 15 and $30 \mathrm{~min}$ of recovery. The blood lactate concentration increases through lactate accumulation when the anaerobic glycolysis-induced lactate production rate exceeds the aerobic glycolysis-induced lactate removal rate during high-intensity exercise ${ }^{14)}$. The higher CRF level and increased lactate removal rate after exercise seen in the exercise group is assumed to be due to improved aerobic-anaerobic efficiency. Moreover, regular exercise increases the density and exchange surface area of the capillary vessels and shortens the diffusion distance between the place of lactate synthesis and the capillary vessel wall, thereby improving the lactate exchange ratio ${ }^{15}$. Such a capacity signifies a rapid recovery from muscle fatigue, which is expected to improve physical motion in response to emergencies.

Taken together, the results of this study show that Taekwondo training as security martial arts improves $\mathrm{VO}_{2 \max }$ and the AT, increases CRF, and improves blood lactate clearance rates. Such results are believed to contribute to the performance of more effective security services in emergencies that may even turn violent.

\section{REFERENCES}

1) Seo BD, Kim DJ, Choi DJ, et al.: The Effect of electrical stimulation on blood lactate after anaerobic muscle fatigue induced in Taekwondo athletes. J Phys Ther Sci, 2011, 23: 271-275. [CrossRef]

2) American College of Sports Medicine: ACSM's Guidelines for exercise testing and prescription, 8th ed. Philadelphia Lippincott Williams \& Wilkins, 2010.

3) Wesserman K, Beaver WL, Whipp BJ: Gas exchange theory and the lactic acidosis (anaerobic threshold). Circulation, 1990, 81: 1114-1130.

4) Svedahl K, MacIntosh BR: Anaerobic threshold: the concept and methods of measurement. Can J Appl Physiol, 2003, 28: 299-323. [Medline] [CrossRef]

5) Borch KW, Ingjer F, Larsen S, et al.: Rate of accumulation of blood lactate during graded exercise as a predictor of "anerobic threshold". J Sports Sci, 1993, 11: 49-55. [Medline] [CrossRef]

6) Nikooie R, Gharakhanlo R, Rajabi H, et al.: Noninvasive determination of anaerobic threshold by monitoring the $\% \mathrm{SpO} 2$ changes and respiratory gas exchange. J Strength Cond Res, 2009, 23: 2107-2113. [Medline] [CrossRef

7) Lauer MS, Francis GS, Okin PM, et al.: Impaired chronotropic response to exercise stress testing as a predictor of mortality. JAMA, 1999, 281: 524-529. [Medline] [CrossRef]

8) Deniz F, Katircibasi MF, Pamukcu B, et al.: Association of metabolic syndrome with impaired heart rate recovery and low exercise capacity in young male adults. Clin Endocrinol (Oxf), 2007, 66: 218-223. [Medline] [CrossRef]

9) Imai $\mathrm{K}$, Sato $\mathrm{H}$, Hori $\mathrm{M}$, et al.: Vagally mediated heart rate recovery after exercise is accelerated in athletes but blunted in patients with chronic heart failure. J Am Coll Cardiol, 1994, 24: 1529-1535. [Medline] [CrossRef]

10) Myers J, Prakash M, Froelicher V, et al.: Exercise capacity and mortality among men referred for exercise testing. N Engl J Med, 2002, 346: 793-801. [Medline] [CrossRef]

11) Howley ET, Bassett DJ, Welch H: Criteria for maximal oxygen uptake: review and commentary. Med Sci Sports Exerc, 1995, 27: 1292-1301. [Medline

12) Pfeiffer KA, Pivarnik JM, Womack CJ, et al.: Reliability and validity of the Borg and OMNI rating of perceived exertion scales in adolescent girls. Med Sci Sports Exerc, 2002, 34: 2057-2061. [Medline] [CrossRef]

13) Kindermann W, Simon G, Keul J.: The significance of the aerobic-anaerobic transition for the determination of work load intensities during endurance training. Eur J Appl Physiol Occup Physiol, 1979, 42: 25-34. [Medline] [CrossRef]

14) Kumagai $S$, Tanaka $Y$, Matsumura A: Relationship of the anaerobic threshold with the $5 \mathrm{~km}, 10 \mathrm{~km}$, and 10mile race. Eur J Appl Physiol Occup Physiol, 1982, 49: 13-23. [Medline] [CrossRef]

15) Fei DY, Arena R, Arrowood JA, et al.: Relationship between arterial stiffness and heart rate recovery in apparently healthy adults. Vasc Health Risk Manag, 2005, 1: 85-89. [Medline] [CrossRef] 